\title{
El valor de la técnica
}

\author{
JOSÉ A. MARÍN-CASANOVA \\ Universidad de Sevilla
}

RESUMEN. Se propone una reflexión sobre técnica y valores, particularmente sobre el valor de la técnica. Primero, en el sentido de la técnica como valor, un valor superlativo, puesto que permite lo más valioso para nuestra especie, su supervivencia. El proceso de realización de este valor produce, a su vez, el artefacto en que consiste la naturaleza humana. Ahora bien, el precio de ese valor técnico es asimismo superlativo, puesto que el vaciamiento técnico de la naturaleza comporta que la especie carezca de valor natural: no hay valores naturales. Los valores hay que crearlos. He aquí el valor de la técnica en el sentido ahora del valor como técnica: valorar es asimismo una operación técnica. Los propios valores aparecen como técnicas, en cuanto tales contingentes y plurales, que no obedecen a ningún fundamento natural, sino a la decisión «insuficientemente» racional de emplearlas. Sin embargo, tal intrínseca artificialidad hace a los valores aún más valiosos.

Hubo un tiempo en que había realidad: el mundo era sólido, estaba lleno de objetos o presencias reales ante un sujeto también real. Pero de ese mundo casi nada queda. La técnica se ha encargado de su vaciamiento. Ya no hay quedar, la vieja permanencia sustantiva ha cedido el lugar a una fugaz eventualidad. Ya es corriente el fuego de Heráclito, la corriente eléctrica que todo fluidifica: la energía es el acto puro
ABSTRACT. This paper intends a reflection about technique and values, particularly about the value of the technique. First, the technique is considered as a value, a superlative value, since it allows the most valuable thing for our species, its own survival. Simultaneously it gives us our nature. The human nature revels itself as an artifact. Now then, the price of that technical value is also superlative, since the technical emptying of the nature makes that the species lacks natural value: there are not natural values. The values must be created. Second, the value is considered as a technique: to value is also a technical operation. The very values appear as techniques, something contingent and plural like every technical thing, and «groundless» because they don't obey to any natural reason, but to the «insufficiently» rational decision of using them. However, such an intrinsic artificiality of the values makes them to be even worthier.

que ha liquidado la resistencia natural. $\mathrm{He}$ ahí la paradoja: cuando triunfa, merced a la técnica, el principio de realidad, la realidad queda debilitada y su recuperación ya sólo puede ser virtual. Ciertamente, cuando la realidad es virtual el principio que la exponga ya no puede ser otro que un principio de artificialidad o de fabulación, un principio fabuloso, porque no es ningún principio. Y éste es el valor de la técnica: 
habernos dejado un mundo sin fondo, desfondado, sin fundamento. Ante este desmayo de lo real cabe, en primer lugar, una actitud de nostalgia, de restauración de la realidad perdida, un sentimiento, o mejor sea decir, un resentimiento de pérdida. Las mentalidades tecnófobas arraigan ahí, la derrota de la naturaleza a manos de la técnica les parece el mayor de los disvalores, un oprobio que reclama venganza: la revuelta de la naturaleza. En cambio, esa situación de desplome técnico del fundamento natural puede ser entendida en términos de oportunidad gozosa, como un valor, un valor que exige mucho valor, el de sustituir lo sólido por lo solidario, el principio de razón suficiente por el de «razón insuficiente», reconociendo que la naturaleza no nos proporciona ninguna coartada para nuestro obrar y que, por consiguiente, el aval de nuestra conducta habrá que construirlo, que hacerlo corriente. El valor de la técnica estriba entonces no ya sólo en la técnica como valor, un valor neutro en tanto que la razón técnica, en su dimensión primaria de respuesta al estímulo en aras de la supervivencia, la compartimos, aunque obviamente en distinta medida, con los extremófilos y los primos primates, un valor neutro a fuer de necesario o automático, sino en el valor como técnica, una técnica en cuya razón están presentes los demás, cuyo valor no es la supervivencia orgánica, la vida, sino la supervivencia de una formalización determinada de la vida humana (la adaptación al otro «medio» ambiente, al medio cultural), la buena vida, un valor interesado a fuer de libre o sintomático. Los valores, en efecto, no pueden ser descubiertos, no son naturales, sino que, en tanto que ficciones, han de ser inventados. Los valores, ficticios todos ellos, siendo principales no son principiales, sino fácticos: hay que creerlos y par pari crearlos. Por eso se requiere tanto valor, porque se trata de una técnica que como tal es contingente, sin fundamento que la soporte más allá de la voluntad «insuficientemente» racional de emplearla, y que además, como toda herramienta, se puede utilizar mejor o peor.

Razonar lo hasta aquí expuesto tan apretada como dogmáticamente es lo que en adelante se hará y de la manera siguiente. Primero, se mostrará esa convulsión de la metafísica propiciada por el desarrollo de la técnica consistente en la paradoja de que haya sido la aplicación del principio de realidad lo que ha liquidado la «realidad». Segundo, se argumentará la convicción de que el principio de realidad no era «real» (natural), que era un constructo, algo artificial, justo el artificio que ha permitido el dominio de la naturaleza, y se asimilará como deriva de tal convicción la noción de «fin de la historia». Tercero, se defenderá que la cuestión de los valores ha de plantearse, por tanto, como algo artificial y que eso, el que no sean naturales, el que no podamos afirmar su existencia «objetiva», sino sólo su «razón insuficiente», lejos de desvalorizarlos los hace, si cabe, más valiosos, a costa - eso sí- de un incremento exigente hasta cotas a veces casi insufribles de nuestra propia responsabilidad ${ }^{\text {. }}$.

Cuando había realidad había resistencia. El mecanismo de superación de la objeción natural era la técnica. En un sentido muy lato, todo ser viviente, si aceptamos la vida como un sistema de procesar información con el objetivo de mantenerse, es un ser dotado de razón técnica, del medio para conseguir el fin de la supervivencia ${ }^{2}$. El estrato más básico de la razón técnica es el de establecer la respuesta a los estímulos de un medio ambiente siempre discretamente resistente o adverso para adecuándose a él seguir con vida. Ésa es la primera manifestación de la técnica, la de servir de interfaz entre el ser vivo y su ambiente de modo que el viviente se adap- 
te al medio. Mediante la adaptación al medio se va alcanzando la aquílea meta: demorar el final de la vida. En esto los humanos estamos en línea continua con las formas más elementales y primitivas de vida, disponemos de un mismo - sin pasar por alto la distinta intensidad de modulación - logos técnico lanzado a la supervivencia: todos los organismos somos biológicos.

Ahora bien, señalada esa continuidad primaria de lo humano con el resto de lo viviente, no cabe duda de que asimismo se puede y se debe señalar una diferencia dirimente entre seres humanos y demás seres vivos incluidos los simios. $\mathrm{Y}$ es que no sólo utilizamos herramientas, como los monos, sino que además las construimos. Es decir, no sólo somos técnicos, sino que también somos tecnológicos. Hemos desarrollado un segundo nivel, continuo y simultáneo con el primero, pero analíticamente discernible, de razón técnica que al parecer es exclusiva de nuestra especie: la tecnología. El objeto de lo tecnológico sigue siendo el que compartimos con la bacteria y con el cefalópodo: sobrevivir. La supervivencia que directamente nos proporciona la tecnología es un valor biológico, el valor tècnológico es el valor biológico humano - aunque en tanto que forma hueca, que formalidad humana, sigue siendo un valor éticamente neutro-, un valor que curiosamente surge de un disvalor, de una minusvalía.

En efecto, la tecnología no deja de estar al servicio de la biología en tanto en cuanto sin tecnología no habría especie humana: es su condición de existencia. El humano es, como tanto repetía Simmel, un Mangelwesen, un ser manco. Ya Nietzsche se había referido a él como das noch nicht festgestellte Tier, el animal aún no estabilizado. Y ésta es la tesis de la técnica como condición de la existencia humana, una tesis que es una prótesis para un ser defectuoso, carente y precario, que para sobrevivir precisa del gigantesco aparato ortopédico de la tecnología como su segunda piel. Ésa es the skin of culture por recordar el best-seller de un afamado mcluhaniano. Pero más allá de la expresión, la idea aquí reivindicada es de cuño orteguiano. Es Ortega quien reconoce que la técnica del humano es una ortopedia supletoria de su invalidez originaria, hasta el punto de que el hombre vendría a carecer de naturaleza por cumplir en él la técnica el papel que cumple en el resto de los vivientes la naturaleza. La técnica es una sobrenaturaleza: la naturaleza humana. Formulado paradójicamente, la naturaleza humana se caracteriza por no tener naturaleza: el hombre no tiene naturaleza, tiene técnica.

Esto es situarse en los antípodas del naturalismo de la tradición metafísica, cuya antonomasia podría representar Rousseau. El ciudadano de Ginebra abominaba, así ya en sus célebres discursos a la Academia de Dijon, del artificio. Onanista confeso, asociaba el mal a todo lo que hacía la mano frente a la pureza del corazón. No le cabía duda: el artificio era el origen del mal: Tout est bien en sortant des mains de l'Auteur des choses; tout dégénère entre les mains des hommes ${ }^{3}$. La tecnofobia incrimina a la técnica en la definición misma del mal. La teodicea leibniciana —esa técnica, no reconocida como tal técnica por ninguno de sus practicantes, de transformación del mal en bien - era prorrogada y prolongada así por Rousseau venciendo la impugnación de Dios, la imputación al creador por la presencia del mal en el mundo, al hacer recaer toda la responsabilidad no en Dios, definitivamente exonerado, sino en el hombre. Pero no en el hombre que es bueno por naturaleza, en el hombre natural, sino en el hombre civilizado, en el hombre social e histórico, en una palabra, en el hombre artificial o técnico. De una tacada no sólo Dios era declarado inocente, sino también el propio hombre, claro que el hombre según la naturaleza. Que nuestro 
Dios nos librara de las luces era lo que gritaba desesperadamente el ginebrino al concluir su argumentación en torno al origen vicioso de las artes, cuyo desarrollo no hace sino expandir el vicio original, unas artes que fueron ocasionando formas de sociedad que al llegar un día, merced a la técnica agrícola, a provocar excedentes en la producción económica hicieron que alguien tuviera la desfachatez de decir «esto es mío», a lo que los simples lo creyeron, dando lugar a la propiedad, origen del mal de la desigualdad entre los hombres. La técnica es un dañino y maligno «suplemento» ${ }^{4}$ de la naturaleza, como el sexo manual lo es del «natural».

Qué distinta es la actitud de Voltaire al elevar con su espléndida metáfora del jardín la técnica a paradigma de vida humana. Travaillons sans raisonner ${ }^{5}$. Frente al razonar metafísico, leibniciano, en Candide, nos encontramos con la apología del trabajo que nos aleja de tres grandes males: el aburrimiento, el vicio y la necesidad. La redención, siempre precaria, vendrá dada, así pues, por la técnica, única forma de amortiguar un mal cuya procedencia es tan incierta como cierta es su presencia y su insuperabilidad. Lejos de «desmalificar» el mal, de bonificarlo y trivializarlo como sucedía en el tándem Leibniz-Rousseau, dotándolo de una razón suficiente otorgadora de transparente legitimidad, tenemos una razón limitada, pragmática, que diríamos hoy día, que en vez de reconciliarnos con una naturaleza amable y amistosa, nos permite hacerle frente como a enemiga hostil. Sólo la técnica con sus luces y artes podrá librarnos, siempre provisionalmente, del mal natural que acaba, siempre triunfante, con nuestra vida.

Pues bien, mutatis mutandis, y no es tanto lo que hay que mudar, la concepción orteguiana de la técnica humana, en lugar de situarla en la periferia de la humanidad e inculparla de todos nuestros males, le otorga una centralidad volteriana. La natu- raleza no es una amiga esperada, sino una adversaria que siempre espera el naufragio de la vida. Merece la pena, aun siendo sobradamente conocida entre nosotros ${ }^{6}$, volver a la meditación de la técnica emprendida por Ortega, pues en él como en nadie es diamantina la idea extendida en el siglo según la cual lo propio del hombre no es la adaptación al medio, sino - podríamos decir - su adopción. Ciertamente, Ortega viene a elaborar la siguiente paradoja: la forma humana de adaptarse al medio es adaptar el medio para sí, adoptarlo. El rendimiento de esta paradójica idea es de enorme peralte para el propósito antinaturalista o artificialista que aquí se defiende - nos va a proporcionar la clave principal-: la técnica no puede concebirse como mero instrumento del hombre al servicio del hombre, porque no hay hombre sin técnica: la técnica es la innatural prolongación natural del humano o la natural prolongación innatural del humano, la técnica humana es una supernaturaleza, algo «sobrenatural». Veámoslo poco a poco.

El filósofo madrileño comienza identificando el «don técnico» del hombre con su especificidad, la de crearse una «circunstancia nueva más favorable» o segregar «una sobrenaturaleza adaptando la naturaleza a sus necesidades». $Y$ es que «la técnica es lo contrario de la adaptación del sujeto al medio, puesto que es la adaptación del medio al sujeto». Lo que le lleva a decir que «eso bastaría para hacernos sospechar que se trata de un movimiento en dirección inversa a todos los biológi$\cos { }^{7}$. Pero eso no significa que el filósofo establezca un hiato abisal entre la especie humana y el resto de las vivientes, una suerte de dualismo kantiano, entre el dominio mecanicista de lo natural, dominio determinante o necesario, y el dominio de la libertad, sino que, frente a un chato o ingenuo biologicismo, constata que la biología humana es una biología invertida, lo que en otros lugares denominará una «bio- 
grafía», porque la vida humana se construye como «reacción contra el entorno, este no resignarse contentándose con lo que el mundo es, es lo específico del hombre»: «un hombre sin técnica, es decir, sin reacción contra el medio, no es un hombre» ${ }^{8}$. Pero esto no es expresión de un asimismo ingenuo humanismo, arbitrario y voluntarista, sino que al humano no le queda otro remedio. De permanecer pasiva ante el medio, la especie sucumbiría, se extinguiría por necesidad. Luego es la propia biología, una biología deficitaria, la que marca el destino extranatural del humano obligándolo a interactuar con el medio transformándolo para sí. Es de este modo cómo la propia «naturaleza» humana requiere otorgarse una naturaleza propia, una «sobrenaturaleza».

Ahora bien, eso que el humano se da es algo que no se da en la naturaleza, que respecto de ella es superpuesto e innecesario: superfluo. En efecto, el humano mediante la técnica no satisface directamente las necesidades que la naturaleza le hace sentir, sino que sobrepone sus propias necesidades a las naturales, reforma esa naturaleza o «circunstancia eliminando en lo posible de ella esas necesidades, suprimiendo o menguando el azar y el esfuerzo que exige satisfacerlas» ${ }^{9}$. La técnica es un ahorro de la necesidad, del vicio y del aburrimiento, como enseña el jardín de las delicias volterianas. Nuestra vida - lo sabemos por Ortega - es lujosa y deportiva. La vida humana además de pretender, como todas, la supervivencia, busca, sobre todo, la confortabilidad, sobre el «estar» el «bienestar». Es el «empeño en estar bien»: «sólo esto le parece necesario y todo lo demás es necesidad sólo en la medida en que haga posible el bienestar. Por lo tanto, para el hombre sólo es necesario lo objetivamente superfluo» ${ }^{10}$.

La afirmación de Ortega es contundente. El autor de la Apología del lujo sonreiría complacido ante el hombre superfeta- rio, aunque el tono de Ortega no es tan mondain, no está pensando ni única ni principalmente en el lujo como refinamiento exquisito, sino que está apuntando a la «esencia» humana, técnica desde el momento más primitivo de la humanidad, y está apuntando a la esencia de la técnica: «esto es esencial para entender la técnica. La técnica es la producción de lo superfluo, hoy y en la época paleolítica» ". Así tenemos la consecuencia más tremenda que podemos extraer a partir del planteamiento orteguiano: frente a la naturaleza tenemos el artificio, frente a lo necesario tenemos lo superfluo, frente a lo real tenemos lo virtual. O si leemos los binomios más allá del enfrentamiento dualista, con gradualidad o discreción paradójica: la humanidad se caracteriza por que su naturaleza es artificio, por que su necesidad es superflua, por que su realidad es virtual Obviamente, esto no significa que literalmente el hombre no tenga ni naturaleza ni necesidad ni realidad, sino que lo que más caracteriza su naturaleza, su necesidad y su realidad es justa y paradójicamente lo más alejado de la naturaleza, de la necesidad y de la realidad. En este sentido el humano es el ser virtual.

Es un opúsculo no tan citado como la «Meditación» el que nos puede hacer comprender mejor nociones orteguianas como que el hombre es el animal fantástico, el novelista de sí mismo, o que la ciencia es poesía. La obrita es «El mito del hombre allende la técnica», una conferencia alemana del Ortega mayor. Ahí se encuentra la justificación de cómo hay que entender la realidad humana como virtual, lo que ciertamente coadyuva a la tesis aquí defendida de que el desarrollo de las nuevas tecnologías pone en cuestión las tradicionales categorías metafísicas de comprensión de lo real: En efecto, tesis dislocadoras de la tradición como que la técnica es el «esfuerzo para ahorrar esfuerzo» ${ }^{12}$, un «esforzarse [del humano] en que haya lo que aún no hay; a saber él, él mis- 
mo» ${ }^{13}$, o como «que la vida no es fundamentalmente como tantos siglos han creído: contemplación, pensamiento, teoría. No; es producción, fabricación, y sólo porque éstas lo exigen, por lo tanto, después, y no antes, es pensamiento, teoría y ciencia» ${ }^{14}$, estas tesis que son todo un esfuerzo técnico subversor del orden metafísico las podemos exprimir en toda su enjundia, si ponemos en paralelo de complementariedad dos frases separadas por unos veinte años. La una, de la Meditación: «La historia del pensamiento humano se reduce a la serie de observaciones que el hombre ha hecho para sacar a la luz, para descubrir la posibilidad de máquina que el mundo lleva latente en su materia» ${ }^{15}$. La otra, de la lección bávara: «Todo pensar es fantasía y la historia universal es el intento de domar la fantasía sucesivamente, en diversas formas» ${ }^{16}$. $\mathrm{Y}$ es que si sintetizamos ambos asertos lo que tenemos es ni más ni menos que la historia humana es la fantástica mecanización del mundo: el hombre se crea creando. La historia es poiesis.

La conferencia lo deja claro: el extrañamiento del hombre y la naturaleza se resuelve en un entrañamiento, en un descubrimiento de que el mundo ha de fabricárselo fabricándose a sí mismo a partir de las riquísimas imágenes de su interior, de su infinita imaginación. Frente al tropismo zoológico hacia el entorno, hacia el exterior, el enfermo animal humano, animal imposible, «entró en sí mismo», se inventó su entorno y de consuno se inventó a sí mismo: nació el «hijo de la fantasía». Su imposibilidad natural se hizo realidad virtual. El hombre es el primer ser real imposible. ¿Cabe mayor subversión metafísica? El propio Ortega lo mantiene en asombrosa combinación de desnudez y delicadeza: «Como enfermo, desde la naturaleza es imposible, pero en la medida en que está ahí, vale como ser real, a pesar de ser al mismo tiempo antinatural. Tendríamos el maravilloso fenómeno de algo que aun siendo imposible es, independientemente de ello, real, lo cual labora violentamente contra toda la tradición filosóficas ${ }^{17}$.

Se puede ser más pesado, pero no más neto. Ortega, frente al «naturalismo» propio de la tradición metafísica, celebra «la victoria de la técnicas, el valor de la técni$c a$. Un valor que no es neutro por cuanto el humano está obligado a interactuar mediáticamente en aras del neto interés de la supervivencia, pero sí éticamente, porque no se está hablando aún de una determinada tecnología frente a otras, entre las que elegir, y, por tanto, valorar, no se está hablando de un forma técnica singular, sino de la formalidad técnica general de la especie humana, una sobrenaturaleza que le ha permitido (y sin la que no le habría sido ni es posible) sobrevivir. Éste es el valor indiscutible de la técnica: «crear un mundo nuevo para nosotros, porque el mundo originario no nos va, porque en él hemos enfermado. El nuevo mundo de la técnica es, por tanto, como un gigantesco aparato ortopédico que ustedes, los técni$\cos$, quieren crear, y toda técnica tiene esta maravillosa y - como todo en el hombre- dramática tendencia y cualidad de ser una fabulosa y grande ortopedias ${ }^{13}$.

Creo que si pasamos del discurso orteguiano al funcionamiento de hecho de las teletecnologías se nos confirma el valor de la tesis artificialista o protésica, y el consiguiente tambaleo de la tesis naturalista, el valor de la prótesis «sobrenatural» frente a la tesis natural. No hace falta suscribir teorías mentalistas como las del antes aludido De Kerckhove, que ven el desarrollo telemático del mundo en clave mcluhaniana, de extensión del cerebro, hasta concebir la web como mente global que engloba las mentes particulares en ella conectadas, para reconocer la disolución del mundo metafísico, el desfondamiento de la vieja naturaleza y sus categorías. $Y$ es que si ya había algo de distal en las tecnologías más rudimentarias, las teletecnologías han logrado distanciar máximamente al humano de la naturaleza. La paradoja de la téc- 
nica exhibida por Ortega, sacar el mundo exterior desde el interior humano se ha hipertrofiado con las nuevas tecnologías, ya que éstas están provocando ahora que sea nuestra imaginación la que desde fuera nos mire. Es decir, que sea el exterior, el imaginario exterior el que configure a la especie, que la naturalidad humana sea prácticamente el sostén de los aparatos protésicos, que lo orgánico sea poco más que el soporte de lo mecánico, que la biología sea sólo la percha de la tecnología. El cyborg, el humano biónico, el transhumano no es una hipótesis de ciencia-ficción, de «fantaciencia», sino cada día más nuestro propio ser.

Y esto, una vez más, ya lo vino a apuntar Ortega en su meditación, al pronunciarse sobre lo que llamó «la técnica del técnico». Viene a reparar ahí nuestro sabio en que si bien las distintas técnicas fueron suplemento de la debilidad constitutiva del ser humano, en principio se usaban sin conciencia de la técnica como capacidad abrogadora del límite natural, mientras que hoy día la conciencia lo es de la ilimitación: «Esta nueva conciencia como tal coloca al hombre, por vez primera, en una situación radicalmente distinta de la que nunca experimentó; en cierto modo, antitética. Porque hasta ella había predominado en la idea que el hombre tenía de su vida la conciencia de lo que no podía hacer, de lo que era incapaz de hacer; en suma, de su debilidad y de su limitación. Pero la idea que hoy tenemos de la técnica... nos coloca en la situación tragicómica... de que cuando se nos ocurre la cosa más extravagante nos sorprendemos en azoramiento porque en nuestra sinceridad no nos atrevemos a asegurar que esa extravagancia - el viaje a los astros, por ejemplo- es imposible de realizar» 19 .

Que la imagen de máxima extravagancia que se le ocurriera a Ortega fuese la hoy ridícula de la viabilidad de la astronáutica, lejos de invalidar su pronóstico, lo refuerza: que algo delirante a la altura de
1933 se llevara a cabo poco más de treinta años más tarde confirma lo que sostenía el pensador. Y si esto es así, entonces resulta que la supresión de lo orgánico no es ninguna broma de Sterlarc, que la hipótesis de Houellebecq en su todavía reciente e impactante novela Particules élémentaires donde se fabula como subtexto una tercera revolución metafísica consistente en el reemplazo, salvo escasos residuos tercermundistas, de la especie humana por otra donde se ha logrado la inmortalidad mediante la supresión de la reproducción sexual, aunque hoy nos resulten tan excéntricas como el viaje a la Luna para D. José y su auditorio, son cuando menos ideas de innegable efervescencia reflexiva.

No obstante, y mientras tal cosa sucede, extraigamos algunas consecuencias de la nueva situación en la que nos ha dejado el triunfo planetario de la civilización tecnológica, pues creo que la conversión del mundo en máquina (en eso que en latín significa proyecto o plan), en el universo de la disponibilidad es parangonable a lo que no sin encendidas controversias se ha llamado con expresión heideggeriana das Ende der Metaphysik, «el fin de la metafísica» y que ya Nietzsche había descrito como nihilismo. En efecto, Heidegger caracterizando el nihilismo en Nietzsche dice que del ser no nos queda nada, que del ser no hay nada. Eso es el nihilismo y en el nihilismo consiste nuestra historia, la historia de Occidente. Y el instrumento aniquilador del ser ha sido la metafísica, cuyo «brazo ejecutor» es la técnica. No interesa aquí o aquí menos aún que en otros lugares toda la parafernalia conceptual heideggeriana, su descortés mística, pero es mérito del alemán haber descrito la historia como progresivo proceso de pérdida de sustancia, de avance de la nada, de olvido del ser ${ }^{20}$. Es asimismo mérito añadido suyo haber descrito la racionalidad de la metafísica como racionalidad técnica: frente al mostrenco enfrentamiento entre episteme y techné, entre scientia y 
ars, Heidegger supo hacer ver que desde el inicio, y más allá de la casualidad onomasiológica, la metafísica consistió en aislar una franja de la realidad, más allá de la naturaleza, metafísica, desde la que controlar toda realidad (ontología) y la realidad toda (teología), de modo que la metafísica como ontoteología vino a operar con una gigantesca sinécdoque reductora del ser a ente. La realidad reducida a cosa, el ser hecho objeto, la tierra llevada a presencia, a presencia de un sujeto que se la representa, que se la representa como siempre a mano, como absolutamente manipulable, siempre disponible, ésta es la mentalidad intrínsecamente técnica de la metafísica y que triunfa en el mundo moderno con su objetivación tecnocientífica. En nuestros días, esos que Heidegger vio presididos por la cibernética como nueva ciencia fundamental, se logra el cumplimiento del modo operativo de la metafísica, pues en ellos se vive la universal objetivación del ser, el mayor olvido del ser a favor de los entes y el mayor olvido de ese olvido.

Propongámonos sustituir en el discurso heideggeriano «ser» por «naturaleza». Si lo hacemos, los dos «méritos» de Heidegger acabados de señalar se vuelven iluminadores de lo que antes comentábamos de Ortega. La historia de Occidente puede leerse como progresiva reducción de la naturaleza, como olvido de la naturaleza, un olvido que se olvida de sí mismo de modo eminente con las nuevas tecnologías. Hoy la naturaleza ha sido abolida ${ }^{21}$. O si no, ha quedado totalmente debilitada o «secularizada», hasta el punto de que casi la sostenemos artificialmente. La naturaleza, paradigma máximo de la reali$\mathrm{dad}$, ha dejado de ser fundamento, lo que - como luego se verá- nos impide un pensamiento fundante. El fundamento ha sido lo buscado por toda nuestra tradición metafísica, e independientemente de que se señalara como fundamento este o aquel otro ente, siempre era asociado a lo natu- ral, esto es, a lo incondicionando, a lo absoluto, a lo necesario. Lo incondicionado, lo absoluto, lo necesario, era la naturaleza metafísica, que, coincidente o no con la física, siempre era expresión, en tanto que conspicuo ontos on, de la máxima resistencia, de aquello irresistible por antonomasia. Pues bien, el artificialismo con su progresiva disolución de la resistencia, de la resistencia natural, ha terminado disolviendo la naturaleza misma, la realidad suprema.

Y ello es paradójico, pues es la aplicación del principio de realidad lo que ha acabado con la realidad. La técnica en su empeño objetivador nos ha terminado revelando que el mundo objetivo es nuestro mundo, la objetivación del sujeto tecnológico. La técnica buscando la máxima fidelidad a lo real nos devuelve nuestra imagen, nos revela la virtualidad de lo real. Es así wie die wahre Welt endlich zur Fabel wurde, es así, como escribe Nietzsche, cómo por fin el mundo verdadero se hizo fábula. La pérdida del sentido general del ser que constata la tecnociencia, el acabamiento o cumplimiento de la metafísica en la universal objetivación del ente, el fin de la «metafísica de la presencia» en las teletecnologías ha terminado produciendo la fabulación del mundo, que la realidad se haga vaga, que adquiera, como han visto Rosen ${ }^{22}$ y Vattimo ${ }^{23}$, los perfiles de lo fantástico, de lo novelesco, de lo que ya no se ve con la nitidez de lo objetivo y cierto, de lo calculable. La realidad se ha aligerado, ha perdido peso y densidad, objetividad en el proceso de objetivización del principio de realidad. Ésa es la mentada paradoja: la ejecución del fundamento ha ejecutado al fundamento. Éste es el resultado de la experiencia no-velada de la realidad.

Aunque la horadación de la naturaleza, la consunción del ser, no ha sido algo subitáneo, sino que es tan largo como la presencia humana sobre la superficie del planeta, las nuevas tecnologías de matriz 
cibernética o informática sí han producido el remate revolucionario del proceso, su corona fantástica. Y es que la extensión del cuerpo, de sus órganos y sentidos, en que consistía la tecnología por así decir «tradicional», la tecnología pesada, se correspondía con lo que se le resistía al cuerpo. Lo primero era el anticuerpo hostil, que proporcionaba la conciencia de la invalidez, la fragilidad y la limitación, de ahí el suplemento protésico de la técnica, el cuerpo expandido tecnológicamente. Pero ahora con la disolución de la resistencia, con el debilitamiento del ser o aligeramiento de la naturaleza las tornas han cambiado. Y la meditación de Ortega lo intuye. Sin nombrarlo, viene a prevenir del nihilismo (pasivo), cuando poco después de advertir de la nueva idea que hoy tenemos de la técnica, según la cual nada nos parece imposible de realizar, afirma: «la técnica, al aparecer por un lado como capacidad, en principio ilimitada, hace que al hombre, puesto a vivir de fe en la técnica y sólo en ella, se le vacíe la vida. Porque ser técnico y sólo técnico es poder serlo todo y consecuentemente no ser nada determinado. De puro llena de posibilidades, la técnica es mera forma hueca - como la lógica más formalista-; es incapaz de determinar el contenido de la vida. Por eso estos años en que vivimos, los más intensamente técnicos que ha habido en la historia humana, son de los más vacíos» ${ }^{24}$. Se ha perdido la ecuación compensatoria entre la técnica y la naturalidad del hombre y «hoy los supuestos técnicos de la vida superan gravemente los naturales, de suerte que materialmente el hombre no puede vivir sin la técnica a que ha llegado. Esto no es una manera de decir, sino que significa una verdad literal» 25 .

En efecto, que hoy el hardware se haya venido a transformar en software y el software se esté transformando en mindware, el que la digitalización signifique que es posible traducir cualquier conjunto de entradas en cualquier conjunto de salidas, vale decir, como suele apuntar Nicholas Johnson, que cualquier contenido puede almacenarse en cualquier soporte o transmitirse por cualquier medio, el que la materia haya sido transmutada en espíritu por la tecnología - si queremos categorizarlo hegelianamente- o lo que es lo mismo, la implosión o contracción de la tierra en coincidencia con la expansión de la racionalidad tecnológica, todo ello es indicativo de la cuasi supresión de la resistencia, de la pérdida de la compensación entre la realidad y la aplicación tecnológica del principio de realidad. Dicho en hipérbole y con prosopopeya: el cuerpo de la tierra se ha librado de sí mismo cuando el intelecto hecho naturaleza ha hecho de la naturaleza intelecto. Asistimos a la fantasmagoría de la realidad. Y en el doble sentido del genitivo: objetivo, pues la realidad se ha hecho fantasma, y subjetivo, pues el fantasma se ha hecho realidad. La técnica pesada era proyección fantástica de nuestros órganos, ahora la ligera es la proyección fantástica de nuestra misma fantasía. Lo que, a su vez, significa que habiéndonos incorporado la naturaleza toda la tierra se ha hecho extensión de nuestro cuerpo y éste, una extensión de la tecnología.

\section{II}

Éste es el mundo en el que la técnica ha suplantado a la historia, el mundo del fin de la historia. Perdido el referente por la tecnología, la tecnología se vuelve referente, aunque esto sea una contradicción en los términos, pues la tecnología siempre ha sido distal y ahora como teletecnología a mayor abundancia. Ella nos ha prolongado protésicamente, siempre ha actuado como mediación que nos alejaba de la inmediatez del agresivo ambiente, nos ha diferido espaciotemporalmente respecto de la contundencia del referente 
natural y ahora resulta que se convierte en el nuevo referente, en condición insuperable de la vida. De alguna manera, sucede como si las tesis derridianas, extraviadas desde un punto de vista realista, se hicieran, bajo el prisma teletecnológico, muy sensatas, «realistas» respecto del nuevo ser. En efecto, las TIC y en especial la $w w w$ parecen generar un ser que siempre se encuentra diferido, tanto espacial como temporalmente, haciendo del ser como presencia, la naturaleza, una ilusión ${ }^{26}$. En el ciberespacio no podemos salir afuera para señalar un referente externo. Así, en cualquier hipertexto de la web sus elementos se encuentran siempre diferidos remitiendo un link a otro sin que se dé un momento originario. En el mundo digital la copia es idéntica a su modelo, no hay original, Ciertamente, lo que se ha llamado la tecnología ligera, en su condición de sobrenaturaleza fantástica, niega un ser unitario y permanente, un punto fundamental donde el presente coincida consigo mismo: siempre hay un retraso originario (una ausencia anterior a cualquier presencia) y una diferencia desde el origen: el satélite difiere todo, la cobertura nunca es en directo. La técnica, y la tecnología de hoy lo ha revelado reemplazando la experiencia natural por una experiencia técnica o simulada, sustituyendo la cosa «real» por un surrogado o «sucedáneo», se presenta como el nuevo significante que «fundamenta» cualquier significado, como el nuevo referente, el «nuevo» sentido. $\mathrm{O}$ no tan nuevo, pues nunca fuimos, en tanto que humanos, naturales, esto es, toda nuestra naturaleza está desde siempre diferida. Ha sido la ilusión logocéntrica, la que creyó en algo tan fértil que ha permitido el desarrollo de la civilización tecnológica occidental, en la existencia de un punto de vista, de una perspectiva natural, una estrategia visual que permitía sostener al mundo en el espacio y analizarlo en el tiempo, técnica que además permitía organizar el pensamiento. Es el procesador del pensamiento que aprendemos en las escuelas de toda la vida. La racionalidad la expresamos de forma perspectivista $y$ estructuramos el mundo, así pues, introduciendo el tiempo en el espacio, es decir, organizando la experiencia de lo que hay como secuencia, seleccionando lo que está en el espacio, ofreciendo una lectura selectiva. $Y$ es que difícilmente se puede desligar el pensamiento de la perspectiva de la adopción griega del alfabeto. El alfabeto permitió procesar la información desligándola de su contexto material o «natural». A diferencia de los pictogramas kanji o de los jeroglíficos, que simbolizan una experiencia concreta con un significado concreto, las letras, que materialmente proceden de su refinado, al no significar por sí solas nada en absoluto pudieron hacer abstracción de las cosas y adoptar infinitas combinaciones. $\mathrm{Y}$ así el pensamiento se hizo libre y crítico. $Y$ desde entonces el mundo ya no fue nunca más el mismo. El pensamiento alfabético cambió el mundo y nos cambió la vida. Fue el primer software de Occidente, la primera gran tecnología que posibilitó la metafísica, el pensamiento artificial, que pretendiéndose natural ha configurado nuestro mundo, ese mundo «teorocéntrico» cuya historia ha alcanzado su «fin», cuando, por así decir, se ha revelado su artificiosidad. La racionalidad tecnológica se asienta en la lógica, que es nuestra primerísima herramienta, nuestra mano interior - parafraseando a la inversa el dicho kantiano-, pero cuando lo comprendemos así, la confusión, que está al origen del vicio logocéntrico, de lo que es herramienta desarrollada con lo que es natural queda atrás y con ella la historia que la amparaba.

En efecto, puede entenderse el polémico «fin de la historia» como el fin del sentido de la historia, de la historia como tiempo dotado de sentido, acaecido cuando la tierra, teatro de la historia, se hace inestable por obra de la técnica, pues ésta no sólo ha vuelto líquida la solidez de la 
tierra, sino que tiene el poder de acabar con ella, de destruir el escenario sobre el que el hombre ha contado su historia. Cuando la tierra era estable o sólida, cuando quedaba ser, la historia se presentaba como historia de salvación, como metarrelato capaz de englobar en su seno de sentido unitario cualquier historia particular, legitimando así el dolor, la desdicha y el resto de los males: la historia lograba la transparencia del mal. Hoy esa historia ya no nos la creemos, no nos aparece ya como el horizonte de la autocomprensión humana. Ese horizonte lo aporta hoy la técnica, pues es ella la que hoy se presenta a los humanos como espacio de su propia comprensión. Ya es un tópico hablar de la «edad de la técnica». Si tomamos en serio la expresión, si hablamos de época técnica, entonces tenemos que estar dispuestos a aceptar que nos hemos salido de la historia. No sólo porque época, por su etimología, signifique «suspensión», espacio o espaciosidad propia, sino porque con la referida expresión no se está diciendo la obviedad de la hegemonía de la técnica, de la superabundancia de aparatos tecnológi$\cos$, sino que la técnica ha hecho época, una época que se autocomprende no a partir de la historia que hemos vivido y narrado, sino a partir de la técnica. La época esta en que del ser no nos queda nada es la época donde la autocomprensión humana se logra merced a la técnica. La técnica ha abierto un espacio interpretativo que se ha despedido de la historia. Y es que el concepto de historia ha vivido de la posibilidad del sentido, de la presencia pasada, presente o prometida del sentido ${ }^{27}$. Luego no puede ser menos que, perdido el sentido de la tierra, que deshecha la alianza entre naturaleza y sentido, se deseche el sentido de una historia que pretendía naturalizarnos. Dicho maximalistamente: suprimida la naturaleza, suprimida la historia, la historia universal. Ya no hay un punto de vista único, una sola perspectiva sino que la historia universal se desmulti- plica en historias sin número, en una pluralidad ${ }^{28}$ de historias: la historia, «naturalista» o esencialista, abre paso a la historicidad, a las muchas historias, a la -en expresión de 0 . Marquard ${ }^{29}$ - «historia multiversal» 30 .

Aun a riesgo de simplificar mucho, se puede decir que la impotencia natural de la que surgía la técnica era sublimada en discursos omnipotentes, de gran poder natural, recordatorios y justificativos del límite infranqueable. A saber: en el mito, en la religión y en el humanismo racioidealista. En el mito griego el límite lo señalan las leyes eternas de la naturaleza, la physis: el límite es físico, el cosmos limita al hombre, el límite natural es cosmológico. En la religión judeo-cristiana el límite lo señala la ley de Dios, el theós creador de la physis: el límite es metafísi$\mathrm{co}$, la potencia absoluta del creador divino limita a la criatura humana, el límite natural es teológico. En el humanismo el límite lo señalan las leyes de la razón (del yo), el yo trascendental dictador de la historia: el límite es ético, la potencia absoluta de la humanidad señala los límites de los hombres empíricos y singulares, el límite natural es antropológico. Siempre ha habido un límite lógico (cosmo-lógico, teo-lógico, antropo-lógico), un límite que se entendía natural. En la época del límite natural la técnica era un obrar manipulador de la naturaleza que no llegaba a poner en cuestión la naturaleza, la naturaleza era su fundamento o condición de posibilidad. La naturaleza trascendía la técnica, la cual nunca alteraba la naturaleza en su conjunto. La naturaleza se resistía, la técnica insistía, pero sin llegar a incidir en los grandes ciclos de la naturaleza, ni en la historia sagrada ni en la historia humana. El obrar técnico siempre quedaba inscrito y circunscrito al horizonte natural.

En la época de la técnica, y cada vez más con el desarrollo y proliferación de las nuevas tecnologías, el límite natural se ha desdibujado, aparece tan difuminado o 
esfumado que el humano se siente más allá de él, en disposición de trascenderlo. El poder de manipulación técnica, de experimentación tecnológica, se aparece sin límites y eso abre un nuevo horizonte: el de la experimentabilidad ilimitada y la manipulabilidad infinita. Hoy la técnica pone al hombre frente a un mundo como disponibilidad cuasi absoluta ${ }^{31}$ y así la naturaleza humana, siempre supuesta, ya no puede ser pensada como antes, como naturaleza. La naturaleza humana ya no puede ser pensada. Habría que hablar, en exageración nietzscheana, del Übermensch, de un sobrehumano o transhumano.

El hombre está anticuado. En efecto, como apuntaba Anders, aunque sin el voluntarismo que encierran sus palabras, «hemos renunciado a pensarnos a nosotros mismos como sujetos de la historia, habíamos colocado otros sujetos de la historia, excepto un sujeto sólo: la técnica... De su curso, de hecho, y de su empleo depende el ser o no ser de la humanidad» ${ }^{32}$. Ya apenas podemos, como se va viendo, demorar más la cuestión de los valores. No obstante, abundemos un poco más en la cuestión previa que estamos tratando, la de la -en expresión de Gehlen- «posthistoria». Caída la inmutabilidad del orden natural, físico-natural, del mito, a manos del orden natural, teológico-natural, de la religión, y caída la inmutabilidad del orden natural-divino, a manos del orden natural-histórico, cuando hoy se tambalea el escenario donde tenía lugar la representación de este último orden, vuelta inestable la Tierra al quedar toda naturaleza como aufgehoben por la técnica, ya no caben ni la historia natural ni la historia sagrada ni la historia humana, ya no cabe la historia en absoluto.

Eso que Kolakovski entendía como el «núcleo suicida» de la Filosofía de la Historia ${ }^{33}$, el que la historia tenga por finalidad su propio final, se ha cumplido, la religión había proyectado la técnica como proyecto de salvación señalando la hetero- geneidad entre la naturaleza física y la humana, haciéndole ver al hombre que su reino no era de este mundo, de este mundo natural, pero la técnica primero llevó a la religión a su crepúsculo al ver el hombre, el hombre secularizado, el humanista, que la salvación podía darse en el mundo histórico, la historia nacida de la visión religiosa del mundo superaba a la religión pero manteniendo la salvación. Hoy la técnica ha acabado con ese humanismo que concebía al hombre como naturaleza dentro de un plan de salvación: el medio técnico ha dejado de ser un instrumento al servicio de la liberación del mal, de la redención, pues ya no hay nada que salvar y ella ya no es concebible como mero instrumento. La técnica tecnológica se ha emancipado ella misma, se ha salvado de cualquier naturaleza, carece de límite natural, $y$, en tanto que no se le propone fines, su mismo proceder es su alimento, sólo aspira a su propia potenciación. Ella no salva, sino que, como el desierto, sólo crece.

\section{III}

$\mathrm{Y}$ es aquí donde aflora el problema de los valores, dado que la técnica como valor, el valor neutro de neutralizar la naturaleza para así dotarse el hombre de una naturaleza, un valor éticamente neutro o desinteresado en tanto que sirve al interés meramente genérico de la supervivencia, del mantenimiento de la vida humana, que es posibilidad misma de la humanización, es indesligable del valor como técnica. Pues si bien es cierto que la formalidad técnica «por sí misma no nos ayuda a decidir a qué especie o a qué cultura sería mejor pertenecer» ${ }^{34}$, y por ello hablamos de su neutralidad, resulta que los humanos nunca nos encontramos existiendo en la mera formalidad, en la abstracción de la supervivencia de la vida, sino siempre en busca de la buena vida. Y ahí ya no cabe hablar 
de la neutralidad del valor de la técnica, del uso automático de la técnica para sobrevivir, pues aunque lo incorporemos como automatismo, el empleo de la técnica nunca fue neutral, el inicio de una técnica nunca es automático, sino sintomático, y según la técnica empleada así ha sido la vida que se ha vivido. Gracias al valor de la técnica en el sentido genitivo objetivo, que ha vaciado a la naturaleza, un valor que en abstracto se presenta como neutral en tanto que condición de la especie, nos damos cuenta de que ese valor nunca es concretamente neutral: la técnica ya no la podemos pensar como neutral respecto de la propia naturaleza humana, precisamente porque sabemos que no hay la naturaleza humana en superlativo singular, sino que la naturaleza humana se modifica según la declinación técnica, se fabrica. Y entonces no podemos separar nunca de la experiencia histórica humana el valor objetivo de la técnica del subjetivo, la técnica como valor del valor como técnica.

Y ello máximamente en nuestros días porque sabemos que la fuerza de la técnica actual es tanto constructiva como destructiva, tiene potencial de sobra para aniquilar la totalidad de la superficie del planeta. Cuando había historia, el humano tenía sus posibilidades de autorrealización y sus abismos escritos previamente, prescritos en la naturaleza, la existencia se resolvía en la conformidad con la naturaleza. Hoy somos conscientes de que esas posibilidades están inscritas en la técnica y la existencia depende de la capacidad técnica de autorregulación. Como piensa Galimberti ${ }^{35}$, decimos que la técnica modifica la naturaleza del hombre, porque disloca el horizonte de su autocomprensión, que estriba ya no en conformarse a la naturaleza, sino en la capacidad de autolimitación del poderío tecnológico. La técnica aloja un inmenso potencial de vida al que es paralelo el potencial de muerte, y la respuesta no nos la puede dar una extinta naturaleza, sino la propia técnica. No en el sentido de la técnica por sí misma, como abstracción neutral, sino en el sentido de que la respuesta no sólo no puede preterir la técnica, sino que habrá de sustanciarse técnicamente. El valor interactúa con el mundo de la técnica, pero no en el nombre de una naturaleza, sino como una técnica: no se trata de escoger entre la técnica y la naturaleza, sino entre una técnica y otra, entre las muchas técnicas ${ }^{36}$.

Vayamos, pese a la crítica constante de fondo al platonismo que enseguida se verá redoblada, a Platón, pues ahora adquiere un relieve inusitado el mito que en el Protágoras ${ }^{37}$ nos cuenta sobre el nacimiento de la cultura. $Y$ es que nos encontramos en la misma embarazosa situación en que Epimeteo, el imprevisor (nomen est omen) había dejado a su hermano Prometeo. Recordemos que Epimeteo repartió entre todos los animales las facultades para sobrevivir y cuando le llegó su turno al hombre ya se le habían agotado, a Epimeteo no le quedaba ninguna atribución para la raza humana. Así que cuando Prometeo lo advirtió, robó a Hefesto y a Atenea su sabiduría técnica, necesaria para la vida, tuvo que robar el fuego (nuestra luz eléctrica, la electricidad que conecta nuestro sistema nervioso con el mundo y lo electrifica), pero no le era dado entrar en la Acrópolis, morada de Zeus, para conseguir lo que le hacía falta además de la sabiduría técnica, la sabiduría política. Y encima Prometeo hubo de sufrir atroz castigo.

Es dudoso que alguien pueda acceder a la morada divina, que pueda dar al hombre la sabiduría política, pero sí podemos decir algo en torno a la naturaleza de los valores, que nos permita al menos ubicarlos, buscarles un sitio. La única pista a nuestro alcance es que precisamente los valores no tienen ninguna naturaleza. No hay valores naturales. En efecto, creo que podemos reinterpretar el mito y figurarnos que si Prometeo no pudo robar la sapiencia política a Zeus, no fue ni por la altura 
de las murallas acropolitanas ni por sus olímpicos guardianes. Murallas y guardianes simbolizan más bien la custodia de la verdad más espantosa, la misma que se escondía -reinterpretando también el Génesis - en la prohibición de comer del árbol de la sabiduría. A saber: que no hay valores, los valores hay que fabricarlos con la sabiduría técnica.

Si del ser no nos queda nada, tampoco nos podía quedar nada del valor. Vale decir, del valor natural. Cuando la modernidad ofreció una ética sin religión, no por ello renunció a concebir valores fundamentales, mantuvo la forma religiosa, la deuda infinita de la religión, bajo la especie del deber absoluto, algo aún más disciplinario al no darse ya la atenuación misericordiosa de la gracia divina. Del deber de la religión se pasó a la religión del deber, un deber que se autocomprendía como deber sin religión. Pero el valor sin Dios era una continuación de la religión por otros medios, los así llamados racionales. En efecto, la virtud laica no sólo prolongaba el orden axiológico fundamental, sino que lo reforzaba al independizar el cumplimiento del deber de cualquier tipo de compensación a posteriori: el deber es a priori. Queda eliminada toda optatividad con miras a un fin, cosa propia de morales antiguas, el deber no puede condicionarse a nada, sería dejarlo en un plano hipotético, someterlo a una espuria heteronomía, a un interés impuro. La moral pura, esto es, sin contaminación religiosa, es autónoma $\mathrm{y}$, por tanto, su imperativo es categórico: el deber por el deber.

Ese deber era un deber natural, no dictado ya por la también natural ley divina, sino por la naturaleza humana. Hoy - claro es - cuando la tecnología ha aliviado a la humanidad de la naturaleza, tanto exterior (física o divina) como interior o humana, «muertos» Dios y el hombre, ya no hay lugar para una moral natural. Las sociedades posmodernas viven el - dicho sea con Lipovetsky - «crepúsculo del deber». La era del deber se ha eclipsado a favor del posdeber, en beneficio de una cultura que prefiere el bienestar al bien, que busca desesperadamente la moral individual, una ética mínima e intermitente de la solidaridad compatible con la primacía narcisista del ego, donde se ha metamorfoseado la virtud, ahora sin obligación ni sanción, y se practica la telecaridad, a la vez que se asiste a las bodas de la acción moral con la bursátil, pero con conciencia verde. En los tiempos de la posmoral la etiqueta ética aparece en todas partes, la exigencia de sacrificio en ninguna. Las democracias no se sustentan ya en el deber cívico, austero y rigorista, sino que consagran los derechos individuales al deseo y la felicidad. En una palabra: «hemos dejado de reconocer la obligación de unirnos a algo que no seamos nosotros mismos» ${ }^{38}$.

Y si esto es así, si la época tecnológica no nos deja una naturaleza a la que adecuarnos, en la que encontrar la pauta de nuestro comportamiento, que nos proporcione una escala axiológica, entonces de nada sirven los intentos de nuestra tradición filosófica que pretendían encontrar una racionalidad que ante el hecho de que la técnica sólo sepa de medios para un resultado, medio a su vez para otro y así ad infinitum, rompiese esa cadena, ese mal infinito y estableciese los «auténticos» fines del hombre, una racionalidad que nos permitiese trazar una frontera entre lo humano y lo inhumano, que nos señalase el valor humano esencial con el que discernir el comportamiento inhumano, ese que es propio de los brutos, por una parte, $\mathrm{y}$, por otra, de los más brutos todavía, los desalmados. Se pensaba que sin un plus de racionalidad sobre la racionalidad técnica de respuesta satisfactoria al medio hostil no era posible justificar la acción ética. Se trataba en definitiva de encontrar una racionalidad exclusivamente humana (aun cuando con pretensiones propias de un dios) que superase el simple fin, comparti- 
do con los otros organismos, de la supervivencia, que exhibiese el fin naturalmente humano.

La aniquilación de la naturaleza nos impide ya esa busca. Por supuesto, que aún habrá quien la lleve a cabo, pero ya no creeremos el resultado de su investigación. Siempre sospecharemos que aquello que llame «naturaleza humana objetiva» no sea sino un heterónimo de sus preferencias subjetivas, vale decir, un intento de extrapolación sinecdóquica de su modo particular de ser a modo universal y, en consecuencia, único, de ser humano. $Y$ no porque uno no pueda tener sus creencias o valores y querer compartirlos, o porque esos contenidos axiológicos sean inventados, sino por pretender pasar por natural y único lo artificial y plural, por querer tener la patente natural, una carta de naturaleza para imponerlos a los demás. La apelación a la naturaleza se convierte en una coartada para validar las acciones propias frente a las vituperables de los demás, lo cual en tanto conducta contra natura, si se restringe, censura, prohíbe o castiga, mejor que mejor, pues no se haría sino restablecer el orden natural quebrantado. Los fanatismos, los fundamentalismos, los totalitarismos, los nacionalismos, en fin, todos aquellos que están dispuestos a que triunfen sus valores ideales, aunque haya que sacrificar cruentamente la vida efectiva (preferiblemente la ajena mucho antes que la propia) siempre han afirmado tener a la naturaleza de su parte.

Negar la coartada natural no significa negar los valores, significa afirmar tan sólo que los valores no están en la naturaleza a la espera de ser descubiertos para que nos conformemos a/con ellos, que no hay nada natural que nos haga o siquiera permita preferir unos valores a otros. El valor de la técnica es que los valores son a su vez técnicos, los valores son creados, artilugios, artefactos, máquinas. Los valores son artificiales y justamente esto es lo que los hace más valiosos, pues siempre ha valido más el producto manufacturado que la materia prima. La manufactura lleva el sello de nuestra fragilidad, de nuestra caducidad, de nuestra finitud. Los valores son una fabulosa contingencia que en cualquier instante puede ser reemplazada por otra, por un disvalor para nosotros. Por eso, si creemos en la cultura de los derechos humanos, es porque nos reconocemos en ellos, y no porque ellos respondan a la «auténtica» naturaleza humana. La cultura de los derechos humanos es un producto precioso y muy delicado, que en cualquier momento se puede perder y que por ello, por razón de su exquisita rareza, conviene defender. Pero si llegase el malhadado día de su pérdida, no habría desaparecido ninguna parte inalienable e inviolable de la naturaleza humana (el mismo hecho de la desaparición descalificaría esos calificativos), sino un producto, seguramente el más hermoso, de la especie humana.

$\mathrm{Y}$ es que los valores no se adquieren por el conocimiento (Velle non discitur, repetía Séneca), no es cuestión de mayor sabiduría moral el obrar bien. Este prejuicio platónico, el intelectualismo socrático, es el responsable de que tradicionalmente se haya intentado una vez tras otra fundar la conducta moral. Pocas cosas menos democráticas y más estomagantes en el gremio filosófico que el desprecio del intelectual ante la conducta «inmoral» de los demás que no son libres porque desconocen su propio yo, «pobrecitos», si se pusieran bajo la disciplina que imparte, seguro que ya sabrían comportarse «libremente». Frente a la vieja fisura entre realidad y apariencias, que tanto ha valido para deshacerse de los «pseudohumanos», de los humanos meramente aparentes (por citar ejemplos del siglo $\mathrm{xx}$ tan sólo: judíos en la Alemania de Hitler, comunistas en la España de Franco, españoles en la Euskal Herria de Otegi, burgueses en la Rusia de Stalin, musulmanes en la Gran Serbia de Milosevic, etc.), la técnica ha hecho añi- 
cos esa distinción, de modo que nos ha puesto en condiciones de prescindir de la realidad (por mucho que haya servido para hacerla operativa) y no para hacer ahora de las apariencias la realidad, sino para comprender que suprimida la noción de realidad (naturaleza), también desaparece la de meras apariencias, vale decir, al haber reducido el fundamento a nada, nos deja sin fundamento: ahora el fundamento es la nada a la que nos quieren reducir los fundamentalistas. Sin fundamento obviamente ya no podemos fundar el bien, pero, y esto es igual de obvio, aunque se olvida pronto, tampoco podemos fundar la violencia, sino que antes bien, podemos desarrollar sentimientos de piedad ${ }^{39}$ por los demás. Luego se trata de cambiar la pregunta, de dejar de lado la pregunta kantiana por lo que sea el hombre y sustituirla por la de la clase de mundo que podemos prepararles a nuestros sucesores, o la de los fines comunitarios que uno pueda perseguir ${ }^{40}$. De este modo uno deja de plantearse la cuestión esencialista de si los derechos humanos y los calabacines tienen distinto estatuto ontológico, para centrarse en la cuestión pragmatista de qué técnica axiológica crear para creer en nosotros.

Ahora bien, que los valores no se puedan fundamentar, que no puedan ser cimentados sobre una naturaleza suprimida técnicamente, no comporta que no se puedan argumentar, que no se pueda ofrecer razones. Eso lo pensaría el racionalista dispuesto a expedir cédulas de irracionalismo a quien no suscriba el suyo, el que tiene como modelo de razón a la razón suficiente, una razón determinante, mathética, demostrativa. Ciertamente no tenemos un cálculo de los valores, un algoritmo axiológico. Pero si no podemos dar pruebas analíticas, sí podemos ofrecer, como quería Perelman ${ }^{41}$, pruebas de esas que Aristóteles llamaba dialécticas, que - eso sí- no tienen la unívoca contundencia de las otras, sino que ofrecen argu- mentos basados en la probabilidad, en la verosimilitud, en la plausibilidad, argumentos plurales. El propio Rorty argumenta a favor de los valores democráticos apelando a las razones del sentimiento moral, a la preferencia por los que son como nosotros y así repudian el sufrimiento ajeno, a la «lealtad ampliada» ${ }^{42}$. En cualquier caso, se trata de reclamar lo que Lipovetsky llama una «razón pragmática y experimental» ${ }^{43}$, o lo que Blumenberg llamaba el «principio de razón insuficiente» ${ }^{44}$, la propuesta interpretativa basada en apreciaciones merecedoras de aceptación, o lo que Ortega había llamado la «razón histórica», que «es precisamente aquello que hasta ahora se ha llamado sinrazón» ${ }^{45}$, para fabricarnos los valores que nos configuren una vida en lugar de otra (la naturaleza es una, la técnica, múltiple), una buena vida, una vida mejor.

$Y$ es que la cuestión es que no tenemos criterios fuertes externos, una ortodoxia más allá de la simple doxa, que aplicar a nuestra historia, a las luchas de genes y «memes» para distinguir los buenos de los malos resultados. La evolución no tiene nada que ver con la evaluación. No hay conexión interna entre ambos expedientes, lo cual no nos impide que podamos, estimulados, por ejemplo, por la responsabilidad - más por su esperanza que por su argumentación - de Jonas, comprometernos a no comprometer las condiciones para la supervivencia indefinida de la humanidad en la tierra. Eso lo supo ver muy lúcidamente Dewey, quien, como Ortega, abandonó la noción de naturaleza humana ahistórica y la sustituyó por la idea de que ciertos mamíferos se han convertido recientemente en capaces de crear un nuevo medio para ellos mismos en vez de simplemente reaccionar a exigencias ambientales. Y aunque rechazó que hubiese una conexión intrínseca o necesaria entre la racionalidad técnica y los valores democráticos, confió en que el desarrollo de las ciencias y las tecnologías aunaran 
eficiencia y tolerancia, pues ahí estaba su utopía social y liberal: que la técnica profundizara en la ruptura democrática con la vieja distinción entre el alto teórico y el bajo artesano, y que así abandonásemos la obsoleta cuestión acerca de la naturaleza humana, para desacralizando, secularizando, desteleologizando la naturaleza, y preocupándonos por rebajar el sufrimiento «pensar en nosotros mismos como partes de un continuum al que pertenencen igualmente amebas y calamares, aunque también los más flexibles, libres e imaginativos humanoides que serán nuestros descendientes» ${ }^{46}$.
Este trabajo forma parte de la investigación realizada en el seno de la Unidad Asociada al CSIC de la Universidad de Sevilla, «CTS», y sirvió de base a la exposición del autor en el Seminario «Técnica y Valores» que tuvo lugar en la madrileña sede del Instituto de Filosofía en junio de 2000.

${ }^{2}$ Cfr. R. Rorty, Pragmatismo y política, Barcelona, Paidós, 1998 , p. 81.

3 Así comienza su Emile Rousseau.

${ }^{4}$ Es inevitable recordar aquí el estudio que Derrida lleva a cabo en su Gramatología del uso rusoniano del «suplemento» para designar siempre la falta de algo «natural» que requiere su suplementación por algo «artificial», como el amor «natural» es suplementado por el «artificial» autoerotismo. Cfr. J. Derrida, «Du supplément à la source: la théorie de l'ecriture», en De la Grammatologie, Paris, Les Éditions de Minuit, 1967, 379-445.

5 Esta frase pronunciada por Martin justo después de que Cándido haya dicho su celebérrimo il faut cul tiver le jardin puede junto con ésta considerarse la mejor lección del cuento volteriano, su moraleja final Estamos ante la única ley que se permite proponer Voltaire, una ley laica que, frente a la inutilidad del teoreticismo de Pangloss (Leibniz), ensalza la poiesi como medio de liberación y sabiduría. No se trata de una protesta de fe irracionalista, sino de una razón pragmática que, lejos de admitir el escándalo del mal, quiere hacer soportable la vida mediante su mejora. Contra toda moral del desespero Voltaire introduce la perspectiva del hombre hecho por y para la acción cuya razón no puede admitir ningún sufrimiento que no sea estricta consecuencia de nuestra ineludible mortalidad, pues el mal que se explica mediante las leyes naturales, reconociéndolo en su naturaleza objetiva, tendrá una razón suficiente, pero no una razón humana. Y es que frente al optimismo de cuño leibniciano con el que replica Rousseau en su Lettre sur la Providence al poema volteriano sobre el desastre de Lisboa, tenemos el «pejorismo», con el que a falta del neologismo «pesimismo» juega epistolarmente Voltaire a la hora de negarse a aceptar la teleologización del mal. El mal no puede ser transparentado y disuelto como mera privación por la razón, una razón así no sabe nada del cuerpo que se duele y grita, es una razón racionalista. Contra esta razón se yergue el Vol taire mayor para defender una razón pragmatista, que no pretende tener razón suficiente, que cede la Razón mayúscula a los racionalistas, para reivindicar, con «razón insuficiente», que no pudiendo extirpar el mal sí podemos - manteniéndonos en constante actividad- hacerle frente para amortiguar y retrasar su fatal efecto.

- A los ya conocidos trabajos de Mitchan, Dust, Conill y Quintanilla Navarro hay que añadir el reciente estudio de I. Echeverría, «Sobrenaturaleza y sociedad de la información», Revista de Occidente, núm. 228 , mayo de 2000 , pp. $19-32$, y el casi simultáneo «Breve excursuso sobre Ortega y la sobrenaturaleza» que incluye en su célebre Los señores del aire: Telépolis y el Tercer Entorno, Barcelona, Destino, 1999, pp. 35-41.

7 J. Ortega y Gasset, Meditación de la técnica (1939), Madrid, Santillana, 1997 (en adelante: $M T$ ), p. 24.

8 Ídem.

9 Ídem.

10 J. Ortega y Gasset, $M T$, p. 26.

i. J. Ortega y Gasset, $M T$, p. 27.

12 J. Ortega y Gasset, $M T$, p. 31.

$13 \mathrm{~J}$. Ortega y Gasset, $M T$, pp. 37-38.

14 J. Ortega y Gasset, $M T$, p. 38.

is J. Ortega y Gasset, $M T$, p. 38 .

16 J. Ortega y Gasset, «El mito del hombre allende la técnica» (en adelante: $M H$ ), en Obras Completas vol. 9, Madrid, Alianza Editorial y Revista de Occidente, 1983, pp. 617-624; p. 623.

17 J. Ortega y Gasset, $M H$, p. 620.

18 J. Ortega y Gasset, $M H$, p. 624.

19 J. Ortega y Gasset, $M T$, p. 58.

${ }^{20}$ Esto es algo que muchos interpretan en clave restauracionista, denunciando la banalización contemporánea, la «era del vacío», en expresión y título de una obra de Lipovetsky, lo que en Heidegger no está tan claro, pues para él kel ser no es sino que acaece», de modo que lo «malo» no es el olvido, sino en todo caso el olvido del olvido del ser. 
${ }^{21}$ Tal vez se podría redescribir al hombre masa como quien precisamente, lejos de darse cuenta de semejante abolición, toma por fruto natural lo que es fruto técnico y consiguientemente resultado de un duro esfuerzo civilizatorio. De ahí la convicción orte guiana de que «la fabulosa técnica actual corría peligro» (J. Ortega y Gasset, $M T$, p. 29).

22 «El mundo empírico es en sí mismo una cons trucción teórica, un artefacto o un poema... Lo empírico es una creación; una creación necesaria, ya que con el advenimiento de la modernidad la naturaleza ha perdido su sustancialidad... La modernidad es una sucesión de perturbaciones revolucionarias que llevan a reemplazar la naturaleza por las poesías. El plural es aquí necesario; tanto cuando se habla de la physis como cuando se menciona a la naturaleza newtoniana debemos emplear el singular, pero no hay una sola poesía. La insurrección cartesiana contra la filosofía y la ciencia escolástica, que al mismo tiempo es, necesariamente, una insurrección contra la historia, encierra en sí el triunfo de la historia, aunque ahora se lo debe entender como historicidad. La historicidad es la historia de la sustitución de la naturaleza por parte de las poesías», leemos en $S$. Rosen: «Futuro anterior», en G. Vattimo: La secularización de la filosofia. Hermenéutica y posmodernidad, Barcelona, Gedisa 1992, pp. 113-133; p. 117.

23 «El desarrollo del mundo científico-técnico, en la forma de mundo de la información generalizada y del consumo de masas, muestra la tendencia de la realidad a disolverse en la vaguedad de lo poéticon se afirma en G. Vattimo, «El consumidor consumidow, en J. Casado y P. Agudíez (comps.): El sujeto europeo, Madrid, Editorial Pablo Iglesias, 1990, pp. 35-46; p. 42.

24 J. Ortega y Gasset, $M T$, pp. 58-59.

25 J. Ortega y Gasset, $M T$, p. 59.

26 Frente a la identidad de la presencia, lo que tenemos es la différance: el ser diferente significa, por un lado, no ser idéntico, es decir, no hay un ser unitario, presente y original; el ser diferente significa, por otro lado, ser interpuesto, retirado o retrasado, es decir, no hay ser primero o inmediato, sino un ser siempre aplazado o retardado. La différance indica que en el origen no hay identidad, sino espaciamiento y temporalización. El ser está espacio-temporalmente diferido, no cabe el ser logocéntrico cuyo significado era previo a su expresion, como origen absoluto del sentido en general, expresado luego por arbitrarios significantes; al revés, todo signo es significante de otro significante, el significado ya está siempre en posición de significante. Por eso il n'y a pas de hors texte; J. Derrida, La dissémination, Paris, Éditions du Seuil, 1972, p. 364

${ }_{27}$ Cfr. Ibid., pp. 389-394.

${ }^{28}$ La pluralidad de historias también se predica de uno mismo: desaparecido el yo trascendental, la última naturaleza humana, como motor de la historia también desaparece como motor de la biografía. Es interesante atender a Vattimo cuando indica que la conciencia puede ser observada como una pluralidad estructurada en forma de sistema reticular acentrado, con lo que ya no cabe la explicable tecnofobia de los filósofos que pensaron la técnica según el modelo «central» del motor, el cual amenazaba con aplastar la libertad personal, pues ésta se potencia en la red (cfr. G. Vattimo, «Es una red sin centro pero nos da un premio: la libertad», Debats., núm. 69, primaveraverano, 2000 , pp. $18-21$.

${ }^{29} \mathrm{Cfr}$. O. Marquard, «Universalgeschichte und Multiversalgeschichte», en Apologie des Zufälligen, Stuttgart, Reclam, 1986, pp. 54-75.

${ }^{30}$ «Hoy, que sería posible técnicamente escribir una historia universal, representar "todo" lo que ocurre, precisamente hoy la misma idea de una historia universal resulta impensable... cuanto más posible técnicamente se vuelve informar sobre todo, tanto más imposible se torna hacerlo desde un punto de vista unitario, hegemónico. Un punto de vista como ése es el que hacía posible, en el pasado, la idea de una historia», se lee en G. Vattimo, «El consumidor...», op. cit., p. 40.

${ }^{31}$ De re esa disponibilidad ya se daba desde la prehistoria mas no de facto ni siquiera de dicto: no sólo no había conciencia de ello, sino que, en todo caso, se tenía conciencia de justo lo contrario. Luego la efectiva disponibilidad ilimitada viene a suponer todo un novum.

32 G. Anders, L'uomo è antiquato, vol. II, Sulla distruzione della vita nell'epoca della terza rivoluzione industriale, Torino, Bollati Boringhieri, 1992, p. 258.

${ }^{33}$ Cfr. L. Kolakovski, El hombre sin alternativa, Madrid, Alianza Editorial, 1970, p. 282.

${ }^{34}$ R. Rorty, Pragmatismo y politica, op. cit., p. 81 .

35 Vid. la parte primera, Simbologia della tecnica: la scena del Caucaso de la ciclópea obra de U. Galimberti, Psiche e techne. L'uomo nell'età della tecnica, Milano, Feltrinelli, 1999, pp. 49-86.

:36 Quizá convenga aquí evocar la constante enseñanza de I. Berlin en torno a la pluralidad y no necesaria compatibilidad de los valores.

37 Cfr. Platón, Protágoras, 321a-322a.

${ }_{38} \mathrm{G}$. Lipovetsky, El crepúsculo del deber. La ética indolora de los nuevos tiempos democráticos, Barcelona, Anagrama, 1994, p. 12.

39 Piedad en el sentido compasivo, caritativo y hermenéutico que va de Schopenhauer a Vattimo, pasando por Dewey o Donald Davidson.

${ }^{40}$ Cfr. R. Rorty, Verdad y progreso. Escritos filosóficos 3, Barcelona, Paidós, 2000, pp. 230 y 340; y Filosofía y futuro, Barcelona, Gedisa, 2002, p. 16.

${ }^{4} \mathrm{Cfr}$. Ch. Perelman y L. Olbrechts-Tyteca, Rhétorique et philosophie: pour une théorie de l'argumentation en philosophie, Paris, PUF, 1952; Ch. Perelman y L. Olbrechts-Tyteca, Tratado de la argumentación. La nueva retórica, Madrid, Gredos, 
1989; y Ch. Perelman, Rhétoriques, Bruxelles, Editions de l'Université de Bruxelles, 1989.

${ }^{42}$ Se trata de la noción de justicia como larger loyality (cfr. R. Rorty, «La justicia como una lealtad más amplia», en El pragmatismo, una versión. Antiautoritarismo en epistemología y ética, Barcelona, Paidós, 2000, 225-247, o en otra traducción: «La justicia como lealtad ampliadas, en Filosofia y futuro, op. cit., pp. 79-99.

${ }^{43}$ Cfr. G. Lipovetsky, op. cit., p. 20.

44 «La tesis capital de toda retórica es el principio de razón insuficiente (principium rationis insufficientis). Es el correlato de la antropología de un ser al que le falta lo esencial. Si el mundo del hombre se corres pondiera con el optimismo de la Metafísica de Leibniz, la cual creía poder ofrecer la razón suficiente por la que absolutamente hay algo y no más bien la nada (cur aliquid potius quam nihil), entonces no habrí ninguna retórica, pues no se daría ni la necesidad
(Bedürfnis) ni la posibilidad de ser eficaz (wirken) con ella... Pero el principio de razón insuficiente no hay que confundirlo con un postulado de prescindencia de razones (Grüinde), así como "opinión" no designa la conducta infundada (unbegründete), sino fundamentada de modo difuso y sin regulación metódica». Es difícil encontrar mejor apoyo a la tesis artificialista que se defiende aquí sobre la necesaria carencia de valores naturales para un ser a quien le falta «lo más esencial», una naturaleza, que estas palabras de $\mathrm{H}$. Blumenberg, Wirklichkeiten in denen wir leben, Stuttgart, Reclam, 1996, pp. 124-125 (Un análisis del rendimiento filosófico de este «principio» que se despide de todo principio se puede consultar en el artículo del autor, «Una sensibilidad metafórica común: Vico y Blumenberg», Cuadernos sobre Vico, $9 / 10,1998$, pp. 109-133).

$45 \mathrm{~J}$. Ortega y Gasset, $M H$, p. 621 .

46 R. Rorty, Pragmatismo y política, op. cit., p. 92. 